la revue La revue pour l'histoire du CNRS

POUR LHISTORE DU CNRS $\quad 24 \mid 2009$

Soixante-dixième anniversaire du CNRS

\title{
Les 70 premières années du CNRS
}

Catherine Bréchignac

\section{(2) OpenEdition}

Journals

Édition électronique

URL : https://journals.openedition.org/histoire-cnrs/9139

DOI : 10.4000/histoire-cnrs.9139

ISSN : 1955-2408

Éditeur

CNRS Éditions

Édition imprimée

Date de publication : 5 octobre 2009

ISSN : 1298-9800

Référence électronique

Catherine Bréchignac, "Les 70 premières années du CNRS », La revue pour l'histoire du CNRS [En ligne], 24 | 2009, mis en ligne le 05 octobre 2009, consulté le 20 mai 2021. URL : http://

journals.openedition.org/histoire-cnrs/9139; DOI : https://doi.org/10.4000/histoire-cnrs.9139

Ce document a été généré automatiquement le 20 mai 2021.

Comité pour l'histoire du CNRS 


\title{
Les 70 premières années du CNRS
}

\author{
Catherine Bréchignac
}

1 Le 19 octobre 2009, le CNRS fête ses 70 ans. Sans rides, sans états d'âme, confiant et ouvert sur l'avenir. Il a gardé la force et l'inventivité de ses premières années. Nos voisins continuent de nous envier, car, au fil du temps, le CNRS est devenu un maillon incontournable de l'intelligence et de la production de nouveaux savoirs fondamentaux. Fort de sa mission originelle, il coordonne les recherches, pratique la pluridisciplinarité et occupe une place plus qu'enviable dans le paysage de la recherche internationale.

2 À quoi cela tient-il ? Aux qualités qu'il n'a cessé d'exalter : la poursuite de l'excellence, la créativité, la réactivité, l'attrait pour la prospective. Les chercheurs confrontent au quotidien leurs pratiques, partagent leurs expériences et réfléchissent à de nouvelles actions communes. Le CNRS est un creuset d'où émanent de nouvelles impulsions, de nouvelles propositions. Mais il ne suffit pas de découvrir, d'inventer, de connaître, encore faut-il valoriser les inventions et les découvertes, renoncer au langage abscons. En un mot, il est aussi nécessaire de faire connaître. Les chercheurs ne parlent pas aux seuls chercheurs. Ils parlent aussi à la société.

3 Certains croient ou font semblant de croire que la recherche repose sur les seuls moyens humains, budgétaires et structurels. C'est une erreur. Elle est faite d'avancées scientifiques, de stratégies, d'idées et de débats. Qui dit stratégie scientifique évoque de grands thèmes fédérateurs qui abordent les questions essentielles. Pour y répondre, une coordination des efforts est nécessaire et demande de connaître intimement le milieu scientifique, ce que le CNRS a su réaliser au cours du temps. Pour faire avancer le front de la connaissance, la recherche doit aussi allier Savoir et Technologie. Ainsi la découverte et la validation des théories fondamentales nécessitent de développer des technologies sophistiquées qui, à leur tour, suscitent des recherches originales.

4 La recherche scientifique c'est le savoir en mouvement. Elle ouvre les yeux et les esprits vers des champs nouveaux de la connaissance qui transforment profondément notre vie. Chercheurs, ingénieurs et techniciens partagent l'ardente obligation de transmettre leur expertise. C'est pourquoi, dans les témoignages et les interviews qui suivent, on découvre la richesse intellectuelle et scientifique du CNRS. La variété des 
métiers de la recherche, les joies et les déceptions, la passion de tous, stimulent un engagement exigeant, déterminé, permanent.

5 Le Comité pour l'histoire du CNRS a su faire parler et écrire celles et ceux qui font vivre nos laboratoires. Je lui en suis reconnaissante, et tout particulièrement à son président, André Kaspi.

\section{AUTEUR}

\section{CATHERINE BRÉCHIGNAC}

Catherine Bréchignac Présidente du CNRS 